Article

\title{
Assessing the Impact of the National Sustainable Development Planning of Resource-Based Cities Policy on Pollution Emission Intensity: Evidence from 270 Prefecture-Level Cities in China
}

\author{
Yuxin Meng ${ }^{1,2}$, Lu Liu ${ }^{1,2}$, Jianlong Wang ${ }^{1,2}$, Qiying Ran ${ }^{1,2} \oplus$, Xiaodong Yang ${ }^{1,2, *}$ and Jianliang Shen $1,3, *$ \\ 1 School of Economics and Management, Xinjiang University, Urumqi 830047, China; \\ mengmeng660510@163.com (Y.M.); liuluprincess@163.com (L.L.); wjllovectt@126.com (J.W.); \\ ranqy@xju.edu.cn (Q.R.) \\ 2 Center for Innovation Management Research of Xinjiang, Xinjiang University, Urumqi 830047, China \\ 3 Center for Arid Region Rural Development Research, Urumqi 830052, China \\ * Correspondence: yxdlovezt@stu.xju.edu.cn (X.Y.); shenjianliang2021@126.com (J.S.)
}

\section{check for} updates

Citation: Meng, Y.; Liu, L.; Wang, J.; Ran, Q.; Yang, X.; Shen, J. Assessing the Impact of the National Sustainable Development Planning of Resource-Based Cities Policy on Pollution Emission Intensity: Evidence from 270 Prefecture-Level Cities in China. Sustainability 2021, 13, 7293. https://doi.org/10.3390/ su13137293

Academic Editor: Antonio Boggia

Received: 19 May 2021

Accepted: 25 June 2021

Published: 29 June 2021

Publisher's Note: MDPI stays neutral with regard to jurisdictional claims in published maps and institutional affiliations.

Copyright: (c) 2021 by the authors. Licensee MDPI, Basel, Switzerland. This article is an open access article distributed under the terms and conditions of the Creative Commons Attribution (CC BY) license (https:// creativecommons.org/licenses/by/ $4.0 /)$.

\begin{abstract}
The question of how to achieve the sustainable development of resource-based cities has been a major concern for the whole world. In response, the Chinese government has introduced the National Sustainable Development Planning of Resource-Based Cities Policy (SDPRP) to address sustainable development issues in resource-based cities. However, few studies have evaluated the environmental effects of the implementation of the SDPRP. Therefore, difference-in-differences (DID) and mediation effect models were applied to investigate the impact of the SDPRP on pollution emission intensity using balanced panel data for 270 prefecture-level cities in China from 2003 to 2018. The statistical results reveal that the SDPRP significantly reduced pollution emission intensity. Robustness test results showed that the conclusions are robust. Furthermore, the inhibitory effect of the SDPRP on pollution emission intensity increased year after year. We also found that the SDPRP can reduce pollution emission intensity by facilitating technological innovation, accelerating digital transformation, and improving human capital level, in which the role of human capital is stronger, while the role of digital transformation is weaker. The heterogeneity results suggest that compared with mature resource-based cities, the SDPRP had a stronger inhibitory effect on the pollution emission intensity in declining resource-based cities. However, the impact of the SDPRP on pollution emission intensities in growing resource-based cities was significant, while it was not significant in regenerative resource-based cities. Similarly, the SDPRP had a significantly greater inhibitory effect on pollution emission intensity in megacities than in large cities, while it increased the pollution emission intensity in small- and medium-sized cities.
\end{abstract}

Keywords: pollution emission intensity; difference-in-differences model; resource-based cities

\section{Introduction}

China's rapid economic and social development could not have been achieved without the support of abundant natural resources [1]. As suppliers of basic energy and important raw materials, resource-based cities have provided most of the resources and energy needed for China's economic development based on their resource endowments [2,3]. Since the reform and opening up in 1978, resource-based cities have produced 52.9 billion tons of raw coal, 5.5 billion tons of crude oil, 5.8 billion tons of iron ore, and 2 billion cubic meters of timber. In order to speed up economic development, change the management system and policies in production that were not in line with production development and build up a market economy system under socialism, the Chinese government implemented a policy of internal reform and external opening up, namely reform and opening up, in 1978. During the First Five-Year Plan period, 53 out of 156 national key construction projects were laid out in resource-based cities, and the amount of investment received 
by resource-based cities accounted for about $50 \%$ of the total investment, which made a substantial contribution toward building a complete industrial system and promoting economic development in China. However, the overexploitation and consumption of resources in resource-based cities caused a huge impact on the ecological environment and social development [4]. For example, the development model of resource-based cities still strongly relies on the development of traditional industries and the exploitation of natural resources, and its modern manufacturing and high-tech industries are still in the primary development stages [5]. Simultaneously, resource-based cities have a weak ability to gather talents, capital, and innovation, causing a serious lack of support and security for alternative industries [6,7]. Some resource-based cities have repeatedly developed low-level projects, such as those with high energy consumption, pollution, and emissions, causing the contradiction between economic development and ecological and environmental protection to become increasingly prominent. [8-12].

Under the current circumstances of rising international political and economic uncertainty and instability, as well as the prominent problems of unbalanced, uncoordinated, and unsustainable economic development in China, resource-based cities are facing serious challenges to their sustainable development, and the task of accelerating the transformation of its economic development model has become very arduous. Therefore, to achieve environmentally sustainable development by accelerating the transformation of the economic model of resource-based cities, the Chinese government enacted the National Sustainable Development Plan of Resource-Based Cities Policy (SDPRP) on 12 November 2013. The plan stipulates 262 resource-based cities, including 126 prefecture-level administrative regions, 62 county-level cities, 58 counties, and 16 municipal districts. The SDPRP's target is to achieve green transformation, enhance sustainable development, and reduce the total amount of pollutant emissions $[13,14]$. The targets of the SDPRP coincide with the current stage of China's strategy for high-quality economic development, which has brought the sustainable development of resource-based cities to a new stage of development. On the one hand, SDPRP guides the development of resources on a large scale and intensively to improve the level of resource conservation and comprehensive use by firmly establishing the concept of sustainable development, strengthening the planning and management of resource development, and strict market access conditions. On the other hand, SDPRP aims to promote green development, circular development, and low-carbon development by strengthening ecological protection and environmental remediation, so as to achieve a positive interaction between resource development and urban development. Therefore, the SDPRP plays a crucial role in implementing sustainable development in resource-based cities. Despite the many practical implications of the SDPRP, few studies have examined the environmental effects that have resulted as outcomes of its implementation. As such, in this exploratory study, we investigated the actual effectiveness of the SDPRP from the perspective of environmental sustainability and mainly answered the following questions: Has the implementation of the SDPRP reduced pollution emission intensity? What are the pathways through which the SDPRP has affected pollution emission intensity? What are the heterogeneity of the impact of the SDPRP on pollution emission intensity in different city sizes and city types? Answering these questions will not only help to inform policy insights for China and developing countries with a similar economic development to China in guiding the green transformation of resource-based cities and achieving quality economic development, but also provide some reference for the evaluation and formulation of relevant policies.

The sustainable development of resource-based cities is not only a long-term, multidimensional dynamic adjustment process, but also a balanced and coordinated development of economic, social, and ecological systems. Resource-based cities are vulnerable to economic downturns because they lack the internal capacity to develop alternative economic functions [15]. Their economic growth is often accompanied by the resource curse effect, with higher vulnerability due to path dependence and lock-in effects [16]. With the increasing contradiction between economic growth and environmental pollution, 
the question of how to reduce pollution emissions in resource-based cities to achieve green development has become a common concern for governments and scholars [17]. Currently, most scholars' research on resource-based cities and their sustainable development mainly include the following aspects.

From a research perspective, the results in this field can be roughly divided into two categories: theoretical research and empirical research. In theoretical research, some scholars have applied theories, such as life cycle theory, industrial structure evolution theory, and sustainable development theory, to the evolution of resource-based cities. Simultaneously, some scholars have innovatively employed the theories of neo-structural economics and ecological science to study the laws governing the transformation of resource-based cities. For example, Murshed and Serino constructed a new structural economics analytical framework for the industrial transformation of resource-based cities [18]. They proposed that the industrial screening of resource-based cities should be closely linked to the life cycles of the cities. Additionally, some scholars have incorporated concepts such as sustainable development and the green economy into the study of resource-based city transformation to ensure that their research is more closely aligned with the current policy status quo in China [19]. For instance, Xie et al. pointed out the difference between green transformation and general economic transformation from multiple perspectives, such as economic, social, corporate, and government perspectives [20]. Regarding empirical research, some scholars have analyzed the current development situation of resource-based cities from the perspectives of resource endowment, environmental regulation, innovation environment, and industrial structure [21-24]. Millar and Choi argue that knowledge is also a valuable resource, including patents, innovation, technology transfer, etc., and that knowledge is one of the most critical resources for developing economies [25]. Qian et al. suggested that there is a resource curse effect in Chinese coal-mining cities, and environmental regulation has an " $\mathrm{N}$ "-shaped relationship with economic growth, as seen when using the system generalized method of moments [26].

Based on the current problems faced by resource-based cities, such as population shrinkage, the resource curse, and economic stagnation, some scholars have explained the future development direction of resource-based cities by considering economic development, income growth, and social welfare [27-29]. Yigitcanlar and Kamruzzaman argue that cities are at the forefront of economic development and that along with rapid urban economic growth and an increasing share of the urban population, the act of enhancing the quality of life at the expense of natural resource depletion and ecological damage often becomes the primary choice for urban development, which is not conducive to long-term prosperity, and therefore sustainable urban development is particularly important [30]. Some of these scholars have also explored the sustainable development of resource-based cities from the perspectives of environmental governance, sustainable development, urban resilience, and ecological carrying capacity, bringing resource and environmental factors into the analytical framework [31,32]. Wang et al. pointed out that a comprehensive evaluation of the environmental carrying capacity of resource-based cities requires full consideration of the synergy between the economic, social, resource, and environmental sub-dimensions, and that the constraints on the comprehensive environmental carrying capacity of mineral-resource-based cities vary from one mineral-resource-based city to another [33]. Ruan et al. applied the grey relational method to analyze the policy factors affecting sustainable development in Yichun, China [34].

In addition, some scholars have estimated the environmental carrying capacity impact on resource-based cities based on specific policies that have been introduced by the Chinese government in recent years. For example, Ruan et al. applied the DID model to assess the impact of the establishment of national high-tech zones on resource dependence in resource-based cities [35]. Yang et al. pointed out that the establishment of a national sustainable development innovation demonstration zone is the primary direction that resource-based cities should go to achieve sustainable development in the future [36]. Li et al. found that sustainable development policies contribute to industrial transformation, 
but that there is significant regional heterogeneity in the characteristics of such policy effects [37]. Similar studies were conducted by Zeng et al., Yang et al., and Yu and Zhang, among others [38-40]. In summary, although the above studies explored the sustainable development and transformation models of resource-based cities in detail through qualitative analyses, quantitative measurements, and simulations, there are few empirical analyses of the impact of the SDPRP on pollution emission intensity in resource-based cities. In particular, there is a lack of research related to assessing the environmental effects of sustainable development policies in resource-based cities, and policy assessment tools based on econometric research methods need to be enriched.

The existing research can be enriched on several levels. First, in terms of research content, this study included not only 108 resource-based cities but also 162 non-resource-based cities. The full permutation polygon synthesis illustration method was applied to calculate the pollution emission intensity by considering wastewater, waste gas, and solid waste, which makes the research more detailed and targeted. Second, the difference-in-differences (DID) method was employed to verify the impact of the SDPRP on pollution emission intensity. Furthermore, the instrumental variable method, counterfactual test, and placebo test were used to test the robustness of the results. Simultaneously, mediation effects were applied to analyze the mechanisms underlying the effect of the SDPRP on pollution emission intensity by technological innovation, digital transformation, and human capital. Finally, according to the heterogeneity in urban population sizes and urban types, this study further considered the impact of the SDPRP on pollution emission intensity.

\section{Theoretical Analysis and Research Hypotheses}

As a crucial strategic guarantee base for energy resources in China, resource-based cities are vital for supporting the sustainable and healthy development of the national economy. The SDPRP takes the accelerated transformation of economic development as its main line of action, and ultimately promotes the sustainable development of resourcebased cities by relying on institutional innovation, technological innovation, and talent construction, as well as the use of information technology, such as the Internet+, big data, and cloud computing. The SDPRP is also an important tool for promoting new industrialization and new urbanization and achieving high-quality economic development [41]. Therefore, this study mainly investigated the internal influence mechanism of the SDPRP on pollution emission intensity from the perspectives of technological innovation, digital transformation, and human capital.

Resource-based cities rely on their rich natural resources to lay the foundation for developing new energy from the perspective of technological innovation. Implementing the SDPRP has not only inspired local governments to develop and apply new materials, such as nanomaterials, high-performance rare earth materials, and renewable materials, but also encouraged local governments to exploit new energy industries, such as wind power, photovoltaic power generation, and biomass energy, in cities with the appropriate conditions to reduce pollution emission [42]. Furthermore, the SDPRP reduces pollution emissions at the source by improving the pollution control technology level; strengthening desulphurization, denitrification, and dust removal in high-energy-consuming and highpolluting enterprises, such as thermal power, metallurgy, chemicals, and building materials, as well as strengthening volatile organic pollutant management, toxic waste gas control, and deep waste treatment [43]. Moreover, implementing the SDPRP accelerates the upgrading of key technologies by local governments, which can effectively control pollutant emissions within the entire production chain.

When implementing the pilot cities, resource-based cities also rely on tools such as the Internet+, cloud computing, and big data to popularize knowledge of energy-saving and emissions reduction and encourage the use of low-carbon products as a means of reducing urban pollution emission levels [44]. Simultaneously, implementing the SDPRP has accelerated the digital transformation of resource-based cities [45]. Through digital services, resource-based cities have not only achieved the orderly development of mineral 
and oil resources but also reduced production, transaction, and management costs [46]. In addition, 5G technology has been popularized in resource-based cities with the enactment of the SDPRP, and more local governments are trying to use 5G technology to transform traditional mining industries to achieve industrial transformation and green production, minimizing the negative impact of enterprises on the ecological environment.

Additionally, the SDPRP meets the diversified needs of resource-based cities for talents by coordinating a pool of professionals with expertise and high skills in pollution control. By relying on enterprises dominated by resource-based industries, resource-based cities can also provide opportunities for relevant professionals to exchange and experiment with technology [47]. At the same time, the spillover effect of human capital will enable resource-based industries to gradually realize sustainable development that is driven by technological progress and management innovation, thereby reducing pollution emissions [47]. Ultimately, the promulgation of the SDPRP will raise awareness of environmental pollution among residents and laborers who have long been working as resource-based industrial development leaders, thus providing the backbone for the green transformation of resource-based cities. Based on the previous analysis of the mechanism of the SDPRP on pollution emission intensity, the following hypotheses were proposed:

Hypothesis 1 (H1). The SDPRP has a significant inhibiting effect on urban pollution intensity.

Hypothesis 2 (H2). The SDPRP relies on technological innovation, digital transformation, and human capital to reduce urban pollution emission intensity.

\section{Methods and Variable Selection}

\subsection{Econometric STRATEGIES}

The difference-in-differences method (DID) is a widely used econometric method in policy analysis that focuses on evaluating the extent to which a particular policy, when implemented in a region, affects a particular aspect of that region. The basic principle of the DID method is to divide the survey samples into two groups: one is the policy object-that is, the "experimental group" —and the other is the non-policy object—that is, the "control group." Based on the information about the experimental and control groups, we could calculate the values of changes in the explanatory variables in the experimental group before and after implementing the SDPRP $[48,49]$. Therefore, the enactment of the SDPRP was treated as a quasi-natural experiment in this study in which cities with the SDPRP enacted served as the experimental group and cities without the SDPRP enacted served as the control group. After that, the DID method was used to analyze the effect of the SDPRP on the pollution emission intensity. Referring to Nawaz et al., the model was set up as follows [50]:

$$
E Q_{i t}=\alpha_{0}+\alpha_{1}\left(T R E A T_{i t} \times T I M E_{i t}\right)+\beta_{n} C O N T R O L_{i t}+u_{i}+\delta_{t}+\varepsilon_{i t}
$$

where $i$ represents a prefecture-level city; $t$ represents the year; $E Q_{i t}$ represents the pollution emission intensity of the $i_{t h}$ of a prefecture-level city in the year $t$; TREAT it is a citygrouping variable, in which the sustainable development planning of resource-based cities is defined as 1 for pilot cities and 0 for non-pilot cities; and TIME it is a time-grouping variable, which is defined as 1 if the SDPRP was implemented in city $i$ in year $t$ or 0 if the SDPRP was not implemented in city $i$. The coefficient of TREAT $T_{i t} \times T I M E_{i t}$ represents the impact of the SDPRP on pollution emission intensity. CONTROL $L_{i t}$ represents a series of control variables, including economic development $\left(R G D P_{i t}\right)$, population density $\left(P O P L_{i t}\right)$, industrial structure upgrading $\left(I N D_{i t}\right)$, infrastructure $\left(J C S S_{i t}\right)$, and financial development $\left(F D_{i t}\right) . u_{i}$ represents an individual-fixed effect, $\delta_{t}$ represents a time-fixed effect, and $\varepsilon_{i t}$ is a random error term. $\alpha_{0}, \alpha_{1}$, and $\beta_{n}$ are the coefficients to be estimated.

As we described in Section 2, the SDPRP affects the pollution emission intensity through technological innovation $\left(T I_{i t}\right)$, digital transformation $\left(D T_{i t}\right)$, and human capital $\left(H U M_{i t}\right)$. Therefore, following Baron and Kenny, we used a three-step approach to verify 
the impact of the SDPRP on the pollution emission intensity [51]. The econometric model was constructed as follows:

$$
\begin{gathered}
E Q_{i t}=\beta_{0}+\beta_{1} \text { TREAT }_{i t} \times \text { TIME }_{i t}+\gamma \text { CONTROL }_{i t}+\mu_{i}+\delta_{t}+\epsilon_{i t} \\
M_{i t}=\alpha_{0}+\alpha_{1} \text { TREAT }_{i t} \times T_{I M} E_{i t}+\omega \text { CONTROL }_{i t}+\mu_{i}+\delta_{t}+\varepsilon_{i t} \\
E Q_{i t}=\varphi_{0}+\varphi_{1} \text { TREAT }_{i t} \times \text { TIME }_{i t}+\theta M_{i t}+\rho \text { CONTROL }_{i t}+\mu_{i}+\delta_{t}+\varepsilon_{i t}
\end{gathered}
$$

where $M_{i t}$ represents the mediation variables, including technological innovation $\left(T I_{i t}\right)$, digital transformation $\left(D T_{i t}\right)$, and human capital $\left(H U M_{i t}\right)$. Based on the three-step test for mediation effects, Equation (2) was used to test the effect of the SDPRP on the pollution emission intensity. If the coefficient $\beta_{1}$ was significantly negative, it implies that the SDPRP significantly reduced the pollution emission intensity. Again, we included the core explanatory variables and the mediation variables in Equation (3), and if the coefficient $\alpha_{1}$ was significant, it means that the SDPRP significantly affected the mediation variables. Furthermore, the core explanatory variables and mediation variables are included in Equation (4). If $\varphi_{1}$ was significant, this indicates that there was a transmission path in which the SDPRP affected the pollution emission intensity. In addition, we used the bootstrap method to test the robustness of the influence mechanism and calculated the share of indirect effects in the total mediation effect.

\subsection{Variable Selection}

\subsubsection{Dependent Variable}

Pollution emission intensity $(E Q)$ is affected by a variety of pollution sources in a complex environment; thus, a single pollution emission intensity indicator cannot objectively and comprehensively reveal the true pollution emission intensity level $[52,53]$. The index system of pollution emission intensity was constructed in terms of three pollution sources, namely, air pollution, water pollution, and solid waste pollution. For the calculation of comprehensive indicators, previous studies mostly used hierarchical analysis, multivariate statistical analysis, the Delphi method, and the entropy method to build the evaluation function of comprehensive indicators [54]. However, the above evaluation method lacks the dynamic consideration of the "time dimension" and serious random defects. Therefore, this study adopted the full permutation polygon synthesis illustration method, which not only provides a comprehensive assessment of pollution emission intensity from a dynamic perspective but also avoids the issue of overlapping information between multiple indicator variables [55-57]. The specific measurement process was as follows:

$$
S_{u}=\frac{\left(U_{u}-L_{u}\right)\left(X_{u}-T_{u}\right)}{\left(U_{u}+L_{u}-2 T_{u}\right) X_{u}+U_{u} T_{u}+L_{u} T_{u}-2 U_{u} L_{u}}
$$

where $u=1,2, \ldots, n ; U_{u}$ represents the maximum value of $X_{u} ; L_{u}$ is the minimum value of $X_{u} ; T_{u}$ is the mean of $X_{u}$; and $S_{u}$ is the normalized index value. Then, Equation (6) was used to calculate the comprehensive index of urban pollution emission intensity:

$$
S=\frac{\sum_{i=j}^{i \neq j}\left(S_{i}+1\right)\left(S_{j}+1\right)}{2 n(n-1)}
$$

where $S_{i}$ and $S_{j}$ represent the individual standardized indicator values for the three pollutants $\left(i, j=1,2, \ldots, n\right.$ and $\left.S_{i} \neq S_{j}\right)$.

\subsubsection{Core Explanatory Variables}

To examine the impact of the SDPRP on pollution emission intensity, we set 108 resource-based cities among the 270 cities implementing the National Sustainable Development Plan of Resource-Based Cities as the experimental group, which was defined using the value 1 (TREAT =1); the remaining 162 cities formed the control group, which was 
defined using the value $0($ TREAT $=0)$. We set the period of 2013-2018 as the time variable for sustainable planning in resource-based cities, which was defined using the value 1 (TIME = 1), and 2003-2012 as the period before the introduction of sustainable planning in resource-based cities, which was defined using the value $0($ TIME $=0)$.

\subsubsection{Control Variables}

To control for the influence of other factors on pollution emission intensity, several control variables, including economic development $(R G D P)$, population density $(P O P L)$, advanced industrial structure (Ind), infrastructure construction (JCSS), and financial development $(F D)$, were introduced. Economic development $(R G D P)$ was characterized using a city's gross regional product divided by the total population at the end of the year [58]. Population density $(P O P L)$ was characterized by the number of people in a prefecture-level city divided by the area of the administrative region. Referring to Pan et al., advanced industrial structure (IND) was measured using the proportion of the total tertiary output value to the total secondary output value [59]. The area of urban paved roads divided by the population of prefecture-level cities was used to measure infrastructure construction (JCSS) [60]. Financial development (FD) was measured using the entire loan balances of financial institutions at each year's end [61].

\subsubsection{Mediation Variables}

Mediation variables, such as technological innovation (TI), digital transformation $(D T)$, and human capital (HUM), were introduced into the study to analyze the mechanisms underlying the effect of the SDPRP on pollution emission intensity. The total number of patents granted for inventions was used to measure technological innovation (TI) [62]. The number of international Internet users per 100 people was used to measure the digital transformation (DT) [63]. Human capital (HUM) was measured using the number of college students per 10,000 people in each prefecture-level city [64].

\subsubsection{Data Resources}

Balanced panel data from the 270 prefecture-level cities in China from 2003 to 2018 were used as the subject of this study. All original data were obtained from the China Statistical Yearbook, the China Urban Statistical Yearbook, and the statistical yearbooks of various cities. For some of the missing data, this study calculated the missing values using linear interpolation. The relevant variable definitions are shown in Table 1.

Table 1. Variable definitions.

\begin{tabular}{ccccc}
\hline Variables & Variable Symbols & N & Mean & Sd \\
\hline Pollution emission intensity & EQ & 4320 & 2.4064 & 1.2583 \\
Economic development & RGDP & 4320 & 10.2102 & 0.8322 \\
Population density & POPL & 4320 & 5.7638 & 0.9043 \\
Advanced industrial structure & IND & 4320 & 0.86329 & 0.4530 \\
Infrastructure construction & JCSS & 4320 & 10.9536 & 7.9239 \\
Financial development & FD & 4320 & 16.0316 & 1.3518 \\
Technological innovation & TI & 4320 & 3.3233 & 1.8254 \\
Digital transformation & DT & 4320 & 1.115 & 1.2552 \\
Human capital & HUM & 4320 & 1.4011 \\
\hline
\end{tabular}

\section{Results}

\subsection{Parallel Trend Test}

An additional important prerequisite for the use of the DID method is that the experimental and control groups satisfy the assumption of parallel trends (i.e., the pollution emission intensity of the experimental and control groups maintained a relatively stable change trend prior to the implementation of the SDPRP). Referring to Qi-ying et al., we discerned whether the experimental and control groups had a consistent trend of change 
before the promulgation of the SDPRP by plotting the time trend of the dependent variable (see Figure 1) [65]. Figure 1 reveals that the evolution trend of the pollution emission intensity in resource-based cities and non-resource-based cities was the same before 2013, indicating that the DID model was suitable for this study.

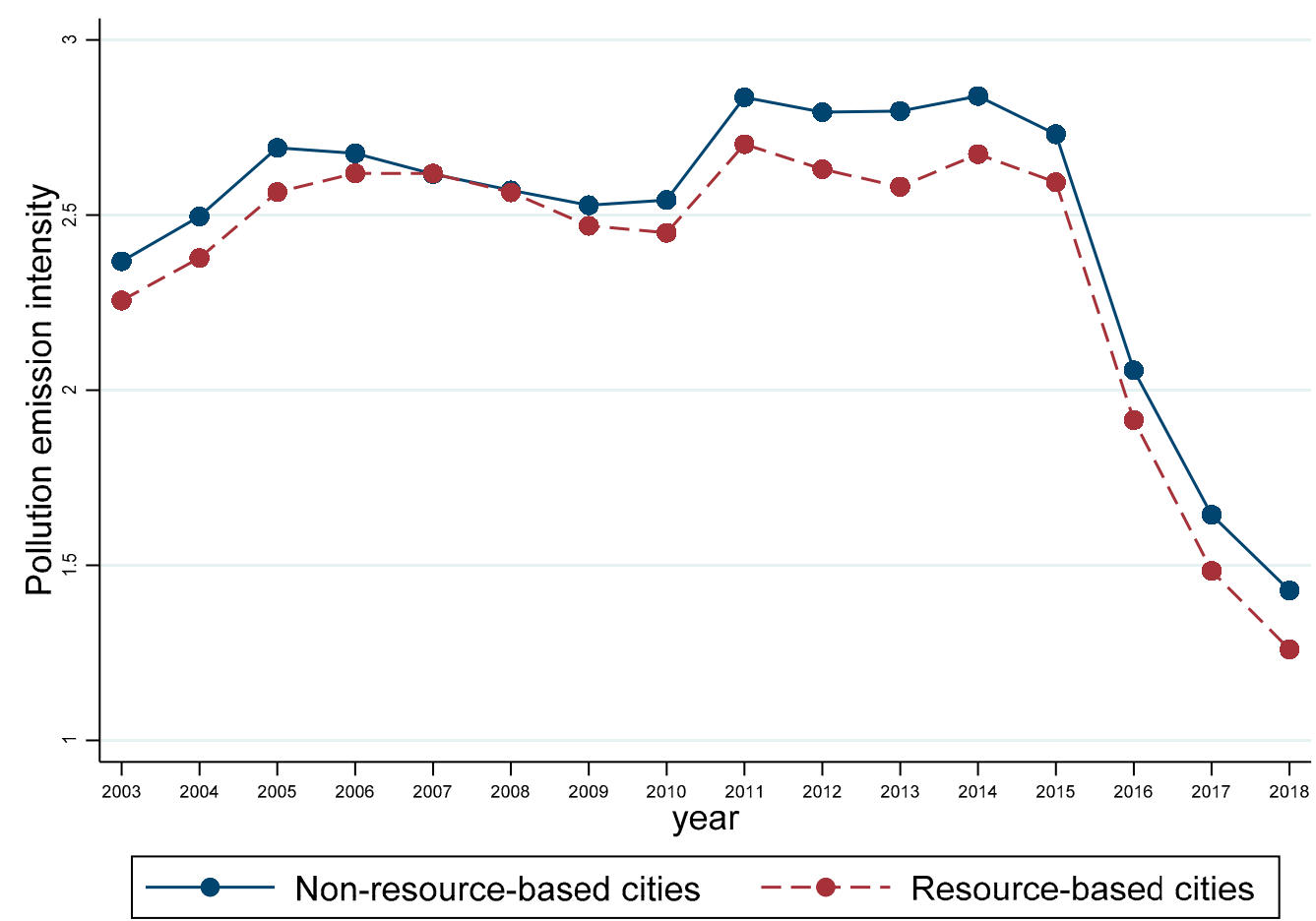

Figure 1. Parallel trends in the dependent variables.

\subsection{Benchmark Regression Results}

In this study, the DID method was used to examine the impact of implementing the SDPRP on the pollution emission intensity. As reported in Table 2, the pollution emission intensity decreased significantly at the level of $5 \%$ after implementing the SDPRP. The SDPRP reduced the pollution emission intensity by an average of $17.05 \%$. Hypothesis 1 was, therefore, verified. In addition, to more rigorously analyze the impact of the SDPRP on pollution emission intensity, we used the DID model to assess the dynamic effect of the SDPRP on pollution emission intensity. The dynamic effect results show that the pollution emission intensity generally had a decreasing trend after implementing the SDPRP. In addition, there was a time lag in the impact of the SDPRP on pollution emission intensity. In the first and third years of implementation, the pollution emission intensity decreased by $1.8 \%$ and $4.29 \%$, respectively, and the effect of the SDPRP on pollution emission intensity showed an upward trend, but the impact was not significant. In the fourth, fifth, and sixth years of implementing the SDPRP, the pollution emission intensity decreased by $72.38 \%$, $118.04 \%$, and $134.4 \%$, respectively, which showed a significant upward trend. Therefore, the effect of implementing the SDPRP on the reduction in pollution emission intensity gradually increased with time, indicating that the SDPRP had a significant dynamic effect on the pollution emission intensity. 
Table 2. Benchmark regression results.

\begin{tabular}{|c|c|c|}
\hline \multirow{2}{*}{ Variables } & \multicolumn{2}{|c|}{ Pollution Emission Intensity } \\
\hline & Average Treatment Effects & Dynamic Effects \\
\hline TREAT $\times$ TIME & $\begin{array}{c}-0.1705^{* *} \\
(0.0594)\end{array}$ & \\
\hline TREAT $\times$ YEAR2013 & & $\begin{array}{l}-0.0180 \\
(0.0416)\end{array}$ \\
\hline TREAT × YEAR2014 & & $\begin{array}{c}0.0507 \\
(0.0439)\end{array}$ \\
\hline TREAT $\times$ YEAR2015 & & $\begin{array}{l}-0.0429 \\
(0.0476)\end{array}$ \\
\hline TREAT × YEAR2016 & & $\begin{array}{c}-0.7238^{* * *} \\
(0.0579)\end{array}$ \\
\hline TREAT × YEAR2017 & & $\begin{array}{c}-1.1804^{* * *} \\
(0.0788)\end{array}$ \\
\hline TREAT × YEAR2018 & & $\begin{array}{l}-1.3440 * * * \\
(0.0896)\end{array}$ \\
\hline Cons & $\begin{array}{l}4.8728^{* * *} \\
(0.6207)\end{array}$ & $\begin{array}{l}2.7961 * \\
(0.0753)\end{array}$ \\
\hline Control variables & Yes & Yes \\
\hline Individual effect & Yes & Yes \\
\hline Year effect & Yes & Yes \\
\hline $\mathrm{R}^{2}$ & 0.1576 & 0.3688 \\
\hline $\mathrm{N}$ & 4320 & 4320 \\
\hline
\end{tabular}

Note: Standard errors are given in parentheses; ${ }^{* * *},{ }^{* *}$, and ${ }^{*}$ indicate significance at the $1 \%, 5 \%$, and $10 \%$ levels, respectively.

\subsection{Analysis of the Influence Mechanism}

The benchmark regression results revealed that the SDPRP had a significant dampening effect on pollution emission intensity. However, as mentioned in Section 2, the SDPRP may influence pollution emission intensity through technological innovation, digital transformation, and human capital. We further used the mediation effects model and bootstrap method to test the influence mechanism of the effect of the SDPRP on pollution emission intensity (see Table 3). Column (1) shows that the SDPRP reduces pollution emission intensity, which passed the significance test at the level of $1 \%$. Column (2) shows that the regression coefficient of the SDPRP was significantly positive at the $1 \%$ level, indicating that the SDPRP significantly promoted technological innovation. Column (3) shows that the regression coefficient of technological innovation was significantly negative at the $1 \%$ level, indicating that technological innovation could effectively reduce pollution emission intensity. Columns (1)-(3) reveal that the SDPRP could reduce pollution emission intensity by increasing the technological innovation level, where the mediation effect was -0.7398 , accounting for approximately $23.11 \%$ of the total effect.

Column (4) shows that the regression coefficient of digital transformation was significantly positive at the $1 \%$ level, implying that the SDPRP promotes digital transformation. The coefficient for digital transformation in column (5) was significantly negative at the $5 \%$ level, indicating that digital transformation was effective at reducing pollution emission intensity. Thus, the SDPRP could reduce the pollution emission intensity by increasing digital transformation. The mediation effect of digital transformation was -0.1445 , accounting for approximately $4.49 \%$ of the total effect. According to columns (6) and (7), the SDPRP could reduce the pollution emission intensity by increasing the human capital level. The mediation effect of human capital was -2.0296 , accounting for approximately $63.20 \%$ of the total effect. Both the Sobel test and bootstrap test were significant, at least at the level of $10 \%$, indicating that technological innovation, digital transformation, and human capital had significant mediating effects. Hypothesis 2 was thus confirmed. Furthermore, we found that human capital had the strongest mediation effect, followed by technological innovation, while digital transformation was the weakest, implying that the SDPRP was 
most effective in reducing pollution emission intensity by improving human capital levels while improving digital transformation has a more limited effect.

Table 3. Influencing mechanism results.

\begin{tabular}{|c|c|c|c|c|c|c|c|}
\hline \multirow{2}{*}{ Variables } & (1) & (2) & (3) & (4) & (5) & (6) & (7) \\
\hline & EQ & TI & EQ & DT & EQ & HUM & EQ \\
\hline TREAT $\times$ TIME & $\begin{array}{c}-3.2114 * * * \\
(0.5535)\end{array}$ & $\begin{array}{c}3.2396 * * * \\
(0.2992)\end{array}$ & $\begin{array}{c}3.4609 * * * \\
(0.5969)\end{array}$ & $\begin{array}{c}0.1797^{* * *} \\
(0.0224)\end{array}$ & $\begin{array}{c}-3.2668^{* * *} \\
(0.5574)\end{array}$ & $\begin{array}{c}0.5389 * * * \\
(0.0432)\end{array}$ & $\begin{array}{l}-4.1818^{* *} \\
(0.5386)\end{array}$ \\
\hline MID & & & $\begin{array}{l}-0.2284^{* * *} \\
(0.0299)\end{array}$ & & $\begin{array}{c}-0.8045 * * \\
(0.3756)\end{array}$ & & $\begin{array}{c}-3.7661 * * * \\
(0.1866)\end{array}$ \\
\hline Cons & $\begin{array}{c}-15.3389 * * * \\
(3.1753)\end{array}$ & $\begin{array}{c}-54.514^{* * *} \\
(1.4891)\end{array}$ & $\begin{array}{l}-2.4964^{* * *} \\
(3.3559)\end{array}$ & $\begin{array}{c}-10.6969^{* * *} \\
(0.1127)\end{array}$ & $\begin{array}{c}-33.1306^{* * *} \\
(4.8853)\end{array}$ & $\begin{array}{c}-9.4400 * * * \\
(0.2169)\end{array}$ & $\begin{array}{c}-11.0271^{* * *} \\
(3.1882)\end{array}$ \\
\hline Control variables & Yes & Yes & Yes & Yes & Yes & Yes & Yes \\
\hline Individual effect & Yes & Yes & Yes & Yes & Yes & Yes & Yes \\
\hline Year effect & Yes & Yes & Yes & Yes & Yes & Yes & Yes \\
\hline Sobel test & & \multirow{3}{*}{\multicolumn{2}{|c|}{$\begin{array}{c}-0.7398 \\
(\mathrm{z}=-6.23, p=0.000) \\
-2.4609 \\
(\mathrm{z}=-4.32, p=0.000) \\
-0.7398 \\
(\mathrm{z}=-4.31, p=0.000)\end{array}$}} & \multicolumn{2}{|c|}{$\begin{array}{c}-0.1445 \\
(\mathrm{z}=-2.069, p=0.039)\end{array}$} & \multicolumn{2}{|c|}{$\begin{array}{c}-2.0296 \\
\mathrm{z}=-10.61, p=0.000)\end{array}$} \\
\hline Bootstrap test(direct effect) & & & & $(\mathrm{z}=-5$. & $\begin{array}{l}8 \\
=0.000)\end{array}$ & $(z=-2$ & $\begin{array}{l}8 \\
=0.023)\end{array}$ \\
\hline $\begin{array}{c}\text { Bootstrap test (indirect effect) } \\
\text { Indirect effect }(\%)\end{array}$ & & & & $(\mathrm{z}=-1$ & $\begin{array}{l}5 \\
=0.052)\end{array}$ & $(\mathrm{z}=-9$ & $\begin{array}{l}6 \\
=0.000) \\
6\end{array}$ \\
\hline $\mathrm{N}$ & 4314 & 4320 & 4320 & 4314 & 4314 & 4314 & 4314 \\
\hline$R^{2}$ & 0.2220 & 0.3518 & 0.1097 & 0.8397 & 0.2165 & 0.5237 & 0.2835 \\
\hline
\end{tabular}

Note: Standard errors in parentheses, ${ }^{* * *}$ and ${ }^{* *}$ indicate significant at the $1 \%$ and $5 \%$ levels of significance, respectively.

\subsection{Heterogeneity Tests}

\subsubsection{Analysis of City-Size Heterogeneity}

According to current research, there is significant heterogeneity in environmental pollution by population size in different classes of cities [66]. Driven by urbanization and industrialization, factors such as capital and labor are flowing into cities in large numbers, resulting in economic agglomeration and expanding the sizes of cities. As larger cities have more educational resources, medical resources, and better infrastructure, they consolidate the city size due to economic agglomeration. However, as the cost of agglomeration increases, the huge consumption of natural resources makes environmental pollution increasingly serious. According to the Circular of the State Council on adjusting the Classification Standard of City Size issued by the State Council in 2014, cities with a population of less than 1 million are defined as small- and medium-sized cities, cities with a population greater than or equal to 1 million and less than 5 million are defined as large cities, and cities with a population greater than 5 million are defined as megacities. The above three groups of city samples were grouped and regressed (http:/ / www.gov. cn/zhengce/content/2014-11/20/content_9225.html (accessed on 29 June 2021)). Table 4 reports that the impact of the SDPRP on reducing pollution emission intensity in megacities $(24.62 \%)$ was significantly greater than that in large cities $(18.45 \%)$. In contrast, in smalland medium-sized cities, the SDPRP had a significant positive contribution to the pollution emission intensity.

Table 4. City-size heterogeneity results.

\begin{tabular}{cccc}
\hline Variables & Megacities & Large Cities & Small and Medium-Sized Cities \\
\hline TREAT $\times$ TIME & $-0.2462^{* * *}$ & $-0.1845^{* * *}$ & $0.4745^{* *}$ \\
& $(0.0748)$ & $(0.0616)$ & $(0.1951)$ \\
Cons & $0.7553^{*}$ & $0.7415^{*}$ & $-0.4911^{*}$ \\
& $(0.5406)$ & $(0.4831)$ & $(1.7708)$ \\
Control variables & Yes & Yes & Yes \\
Individual effect & Yes & Yes & Yes \\
Year effect & Yes & Yes & 160 \\
$\mathrm{~N}$ & 1499 & 2661 & 0.6721 \\
$\mathrm{R}^{2}$ & 0.1138 & 0.1166 &
\end{tabular}

Note: Standard errors in parentheses, ${ }^{* * *},{ }^{* *}$, and ${ }^{*}$ indicate significant at the $1 \%, 5 \%$, and $10 \%$ levels of significance, respectively. 


\subsubsection{Analysis of City-Type Heterogeneity}

There are a large number of resource-based cities in China, and their degree of resource exploitation varies, resulting in significant heterogeneity in their economic development levels and pollution emission intensities. Regression analysis based on the overall sample may obscure the internal differences between cities under different resource and environmental conditions. According to the planning of the National Sustainable Development Plan of Resource-Based Cities (2013-2020) formulated by the Chinese Government, resource-based cities were classified into four types (growing, mature, declining, and regenerative) to explore the heterogeneous effects of the SDPRP on the pollution emission intensity (see Table 5). We found that the role of the SDPRP on pollution emission intensity in declining resource-based cities was significantly higher than that in mature resource-based cities $(27.58 \%>13.09 \%)$. In regenerative resource-based cities, the effect of the SDPRP on pollution emission intensity was negative but not significant. In growing resource-based cities, the SDPRP contributed significantly to the pollution emission intensity.

Table 5. City-type heterogeneity results.

\begin{tabular}{|c|c|c|c|c|c|}
\hline Variables & Full Samples & $\begin{array}{c}\text { Mature } \\
\text { Resource-Based } \\
\text { Cities }\end{array}$ & $\begin{array}{c}\text { Growing Resource } \\
\text { Cities }\end{array}$ & $\begin{array}{c}\text { Declining } \\
\text { Resource-Based } \\
\text { Cities }\end{array}$ & $\begin{array}{c}\text { Regenerative } \\
\text { Resource-Based } \\
\text { Cities }\end{array}$ \\
\hline TREAT $\times$ TIME & $\begin{array}{c}-0.1321 * * * \\
(0.0503)\end{array}$ & $\begin{array}{c}-0.1309 \text { ** } \\
(0.0555)\end{array}$ & $\begin{array}{c}0.4904^{* *} \\
(0.1941)\end{array}$ & $\begin{array}{c}-0.2758 * \\
(0.1808)\end{array}$ & $\begin{array}{l}-0.1580 \\
(0.1287)\end{array}$ \\
\hline Cons & $\begin{array}{c}1.6367^{* * *} \\
(0.2812)\end{array}$ & $\begin{array}{c}3.3817^{* * *} \\
(0.3699)\end{array}$ & $\begin{array}{c}5.6391 * * * \\
(1.2846)\end{array}$ & $\begin{array}{c}2.7967 * * \\
(1.1097)\end{array}$ & $\begin{array}{c}0.0573^{* *} \\
(0.8049)\end{array}$ \\
\hline Control variables & Yes & Yes & Yes & Yes & Yes \\
\hline Individual effect & Yes & Yes & Yes & Yes & Yes \\
\hline Year effect & Yes & Yes & Yes & Yes & Yes \\
\hline $\mathrm{N}$ & 2652 & 1966 & 206 & 240 & 240 \\
\hline $\mathrm{R}^{2}$ & 0.2094 & 0.2359 & 0.3306 & 0.2163 & 0.3141 \\
\hline
\end{tabular}

Note: Standard errors in parentheses, ${ }^{* * *},{ }^{* *}$, and * indicate significant at the $1 \%, 5 \%$, and $10 \%$ levels of significance, respectively.

\subsection{Endogenous Test}

The results in Table 2 confirmed that the SDPRP had a significant inhibitory effect on the pollution emission intensity. Although we included some of the factors that affect pollution intensity to address the endogeneity issue, some other factors may have been overlooked, thus causing bias in the estimation of the empirical results. To obtain more reliable results, we used the instrumental variables method to test the above study results. Referring to $\mathrm{Lu}$ et al., the air ventilation coefficient was used as a tool variable. On the one hand, the air circulation coefficient is determined using the geographical and climatic conditions of the city, which agrees with the exogenous hypothesis. On the other hand, the magnitude of the air circulation coefficient is inversely proportional to the air pollution concentration, which is consistent with the hypothesis of the correlation of instrumental variables. The value of IV denotes the air circulation coefficient, which uses wind speed information at decimeter height and boundary layer height from the European Centre for Medium-Range Weather Forecasts ERA dataset matched to latitude and longitude for Chinese cities from 2003 to 2018 [67]. Table 6 reports that the F statistics in the first stage were greater than 10 , indicating that the selection of tool variables was effective. In the second stage, the regression results of tool variables were consistent with the benchmark regression results, thus verifying that the SDPRP has a significant inhibitory effect on pollution emission intensity. 
Table 6. Endogenous test results.

\begin{tabular}{ccc}
\hline \multirow{2}{*}{ Variables } & First Stage & Second Stage \\
\cline { 2 - 3 } & TREAT $\times$ TIME & EQ \\
\hline IV & $0.2340^{* * *}$ & \\
TREAT $\times$ TIME & $(0.0727)$ & $-2.2128^{* *}$ \\
Cons & & $(0.9827)$ \\
& $1.5457^{* * *}$ & $7.3296^{* * *}$ \\
Control variables & $0.3997)$ & $(1.8817)$ \\
Individual effect & Yes & Yes \\
Year effect & Yes & Yes \\
$N$ & Yes & Yes \\
$\mathrm{R}^{2}$ & 4320 & 4320 \\
F-value & 0.4115 & 0.1007 \\
\hline
\end{tabular}

Note: Standard errors in parentheses, ${ }^{* * *}$ and ${ }^{* *}$ indicate significant at the $1 \%$ and $5 \%$ levels of significance, respectively.

\subsection{Robustness Test}

\subsubsection{Counterfactual Test}

The DID method was applied on the premise that there would be no significant difference in pollution emission intensity between the experimental and control groups over time. Therefore, referring to Tang et al., the years 2010 and 2011 were used as the time of implementation of the SDPRP to verify the robustness of results (see Table 7) [68]. Table 7 reveals that the estimated coefficient of the SDPRP was positive but not significant, indicating that the SDPRP had no significant impact on the pollution emission intensity before 2013. The implementation of the SDPRP could indeed significantly reduce the pollution emission intensity.

Table 7. Counterfactual test results.

\begin{tabular}{ccc}
\hline Variables & YEAR-2010 & YEAR-2011 \\
\hline TREAT $\times$ TIME & 1.1803 & 1.1521 \\
& $(0.7718)$ & $(0.7763)$ \\
Cons & $(0.7718)$ & $(0.77630)$ \\
& 4320 & 4320 \\
Control variables & Yes & Yes \\
Individual effect & Yes & Yes \\
Year effect & Yes & Yes \\
$\mathrm{N}$ & 4320 & 4320 \\
$\mathrm{R}^{2}$ & 0.1603 & 0.1626 \\
\hline
\end{tabular}

\subsubsection{Placebo Test}

A sample of 270 cities in the study was randomly sampled 1000 times, with 108 cities randomly selected in each sample as a dummy experimental group and the remaining 162 cities selected as a control group for the placebo test. In addition, the kernel density distribution of the 1000 estimated coefficients was plotted (see Figure 2). We found that the absolute $t$-value for most of the estimated coefficients was lower than 2 ( $p$-value $>0.1)$, indicating that none of the estimated coefficients for SDPRP were significant in the 1000 random samples. Thus, the placebo test also confirmed the robustness of the findings in this study. 


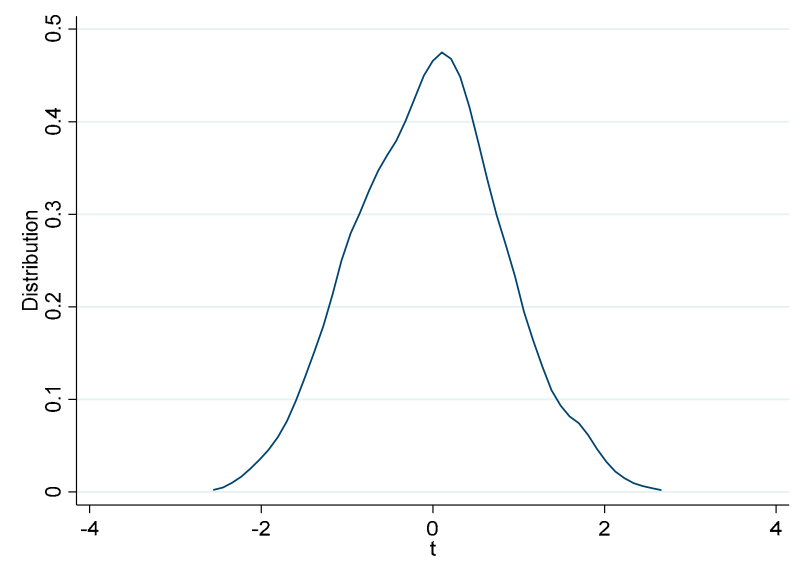

Figure 2. Placebo test results.

\subsubsection{Removing the Interference of Other Related Policies}

The New Environmental Protection Law, the strictest environmental protection law in history, was implemented in 2015. The Chinese government legislated a legal responsibility for environmental governance to reduce the pollution emission intensity. As such, the effect of the SDPRP on the pollution emission intensity may have been affected by the implementation of the New Environmental Protection Law. Therefore, we precisely identified the energy-saving and emission-reduction effects of the SDPRP by excluding the New Environmental Protection Law (2015-2018) (see Table 8). We found that the coefficient of Treat $\times$ time was significantly negative at the level of $1 \%$, indicating that the study results are still robust after excluding other policy interferences.

Table 8. Results after removing the interference of other related policies.

\begin{tabular}{cc}
\hline Variables & EQ \\
\hline TREAT $\times$ TIME & $-9.9771^{* * *}$ \\
Cons & $(0.9277)$ \\
& $18.0690^{* * *}$ \\
Control variables & $(5.93)$ \\
Individual effect & Yes \\
Year effect & Yes \\
$N$ & Yes \\
$\mathrm{R}^{2}$ & 2969 \\
\hline
\end{tabular}

Note: Standard errors in parentheses, ${ }^{* * *}$ indicate significant at the $1 \%$ levels of significance.

\subsubsection{Replacing the Dependent Variable}

Some scholars have suggested that pollution emission intensity is closely related to GDP [69]. To ensure the robustness of the findings, the empirical results were retested using the DID method after the dependent variable was remeasured (the ratio of pollution emission intensity to GDP was applied to measure the dependent variable) (see Table 9). Table 9 reveals that the directionality and significance of the coefficient of TREAT $\times$ TIME were generally consistent with the benchmark regression results, again indicating that the study's results are robust. 
Table 9. Replacement of dependent variable results.

\begin{tabular}{|c|c|c|}
\hline \multirow{2}{*}{ Variables } & \multicolumn{2}{|c|}{ Pollution Emission Intensity } \\
\hline & Average Treatment Effects & Dynamic Effects \\
\hline TREAT $\times$ TIME & $\begin{array}{c}-0.3234^{* * *} \\
(0.0773)\end{array}$ & \\
\hline TREAT × YEAR2013 & & $\begin{array}{c}-0.6279^{* * *} \\
(0.1058)\end{array}$ \\
\hline TREAT × YEAR2014 & & $\begin{array}{c}0.5726^{* * *} \\
(0.1135)\end{array}$ \\
\hline TREAT $\times$ YEAR2015 & & $\begin{array}{c}-0.6582^{* * *} \\
(0.1168)\end{array}$ \\
\hline TREAT $\times$ YEAR2016 & & $\begin{array}{c}-1.3425^{* * *} \\
(0.1300)\end{array}$ \\
\hline TREAT $\times$ YEAR2017 & & $\begin{array}{c}-1.9344^{* * *} \\
(0.1540)\end{array}$ \\
\hline TREAT $\times$ YEAR2018 & & $\begin{array}{l}-1.9861^{* * *} \\
(0.1358)\end{array}$ \\
\hline Cons & $\begin{array}{l}-5.7586^{* * *} \\
(0.3824)\end{array}$ & $\begin{array}{c}-8.4452^{* * *} \\
(0.0753)\end{array}$ \\
\hline Control variables & Yes & Yes \\
\hline Individual effect & Yes & Yes \\
\hline Year effect & Yes & Yes \\
\hline $\mathrm{R}^{2}$ & 0.2395 & 0.3955 \\
\hline $\mathrm{N}$ & 4320 & 4320 \\
\hline
\end{tabular}

Note: Standard errors in parentheses, ${ }^{* * *}$ indicate significant at the $1 \%$ levels of significance.

\section{Discussion}

\subsection{Discussion of the Benchmark Regression Results}

Table 2 reveals that the SDPRP could significantly reduce pollution emission intensity in terms of both the static average treatment effect and the dynamic treatment effect introduced in each year of implementation of the system. This can be explained in terms of the following aspects. First, the implementation of the SDPRP raised the environmental access threshold permit and pollution emission standards, and backward production capacity and enterprises that violated environmental requirements were firmly and promptly eliminated [70]. The strict emission standards, in effect, increased the barriers to entry for polluting enterprises, and the implementation of the backward capacity phase-out initiative was a further improvement to the exit mechanism for polluting enterprises. For enterprises aiming at profit maximization, whether from the perspective of pollution control cost or long-term healthy development in the future, they will be motivated to upgrade production technology and use cleaner production equipment to a certain extent, which will play a positive role in pollution reduction. Second, the implementation of the SDPRP was conducive to the agglomeration of various production factors for the replacement of traditional industries (i.e., industries with high pollution, high energy consumption, and high emissions) to realize the large-scale, intensive, and scientific utilization of resources [71]. Simultaneously, the scale effect of pollution treatment brought about by industrial agglomeration could effectively reduce the cost of treating the environment, which will improve environmental quality. Finally, the implementation of the SDPRP accelerated industrial development in the field of energy conservation and environmental protection, causing industrial diversification in resource-based cities. Industrial diversification and new clean industries, such as energy conservation and environmental protection, will promote industrial transformation and upgrading, not only making the industrial structure cleaner and greener but also helping to reduce the intensity of pollution emissions. Moreover, with the continuous increase in the implementation years of the SDPRP, the quality of the SDPRP is also gradually being refined such that the inhibition effect of SDPRP on pollution emission intensity is also continuously being strengthened. 


\subsection{Discussion of the Influencing Mechanism Results}

Table 3 reports that the SDPRP could reduce the pollution emission intensity through innovation capacity, digitalization, and human capital. From the perspective of innovation capacity, the SDPRP accelerated the R\&D innovation and application of production technology, environmental protection technology, and energy-saving technology by enterprises, which improved the front-end management capacity regarding environmental pollution. Moreover, the technological advances brought about by the SDPRP enhanced the ability to systematically manage relevant pollution data, thus improving the back-end management capacity of environmental pollution. Furthermore, technological innovation in resourcebased cities could not only improve resource utilization but also promote the application of low-carbon technologies throughout the production process, thereby effectively controlling pollution emissions at the production end.

In terms of human capital, the pilot policy stipulates that resource-based cities are required to enhance the overall human capital level and meet the diversified needs of resource-based cities for talents by coordinating the construction of various types of talent teams, such as professional and technical, highly skilled, and social work teams. On the one hand, the pilot policy directly improved the level of pollution management technology in high-energy-consuming and high-polluting enterprises, such as desulphurization, denitrification, dust removal, and deep sewage treatment, by vigorously promoting the exchange and training of professional, technical, and management personnel and training some pollution industry governance professionals and R\&D personnel for clean production. On the other hand, the sustainable development of resource-based cities relies on the unfolding of human behavior, which is the carrier of all socio-economic activities. Human capital levels are the fundamental driver of social development, and all soft power, such as technology, institutions, management, innovation, and culture, is the result of human intelligence. The enhancement of human capital ensures a stable transition in terms of population quantity and quality in resource-based cities as a way to reduce the pollution emission intensity.

From the perspective of digitalization, the implementation of the pilot policy increased digital infrastructure development in resource-based cities. The digitalization of resourcebased cities not only contributed to the dissemination, sharing, clustering, and exchange of knowledge, but also had a positive impact on the improvement of production efficiency, clean equipment, and pollution control technologies to ultimately reduce pollution emission intensity. Second, the pilot policy accelerated the rapid development of digital industries with high technological content, low energy consumption, and high industrial added value, whose industrial attributes are resource-saving and environmentally friendly. Simultaneously, the integration of digital industry and industrialization led to the transformation and upgrading of traditional industries, resulting in a gradual increase in the proportion of tertiary industries. This change in industrial structure is also conducive to reducing energy consumption and environmental pollution. Finally, with the improvement of digitization level, more resources and production factors will also be concentrated in resource-based cities, while the positive externalities and economies of agglomeration scale will reduce the pollution emission intensity.

\subsection{Discussion of Heterogeneity Test Results}

\subsubsection{Discussion of City-Size Heterogeneity Results}

The results in Table 4 indicate that there was significant heterogeneity in the effect of the SDPRP on the pollution emission intensity for different sized cities. It is to be expected that compared with large cities, megacities are better equipped in terms of infrastructure, education, and technology, and they are also more capable of mobilizing resources to reduce their pollution emission intensity. For small- and medium-sized cities, however, the pilot policy could significantly increase the pollution emission intensity. On the one hand, due to the siphoning effect of large cities, the flow of capital, labor, and other factors from small- and medium-sized cities to large cities increased the cost of dealing with 
pollution in small- and medium-sized cities. In addition, the economic development of small- and medium-sized cities is not as high as that of large cities, and they are not able to match the technological capacity to treat pollution. On the other hand, many smalland medium-sized cities have excellent natural resources and a high potential for resource development. However, many local governments in small- and medium-sized cities have been exploiting resources and neglecting local pollution control in the process, to develop the local economy and maximize profits, resulting in small- and medium-sized resource cities exacerbating their pollution emission intensity.

\subsubsection{Discussion of City-Type Heterogeneity Results}

Table 5 reveals that in both mature and declining resource-based cities, the SDPRP significantly reduced the pollution emission intensity; in regenerative resource-based cities, the SDPRP did not reduce the pollution emission intensity. In contrast, the SDPRP significantly contributed to pollution emission intensity in growing resource-based cities. As the mineral resources available in declining resource-based cities for development tend to be depleted and economic development lags, it results in increased costs of energy use. To reduce the cost of energy use, local governments are encouraging technological development through financial and taxation means to improve the efficiency of resource use with the ultimate goal of saving resources. With the general improvement in energy utilization technology, pollution emission intensity decreased accordingly. Mature resourcebased cities are at a stable stage of resource development, with strong resource security and high energy efficiency, such that the effect of pollution abatement was not as high as in declining resource-based cities. Regenerative resource-based cities are freed from resource dependence, and their economy and society have started to step into a benign development track, which is a pioneering area for resource-based cities to transform their economic development mode, thus ultimately having a significant effect on pollution emission intensity. It is worth noting that in growing resource-based cities, implementing the SDPRP instead exacerbated the pollution emission intensity. As the growing resource-based cities are in the ascendant stage of resource development, not only did the non-standard order of resource development lead to a low entry threshold for enterprises, but the high intensity of resource development also caused high pollutant emission intensity.

\section{Conclusions and Policy Implications}

The DID method was employed to examine the impact of the SDPRP on pollution emission intensity using the balanced panel data of prefecture-level cities in China from 2003 to 2018. The statistical results show that the SDPRP significantly reduced the pollution emission intensity. Since implementing the SDPRP, the pollution emission intensity was reduced by an average of $17.05 \%$. In addition, following the implementation of a series of robustness tests, such as the parallel trend test, tool variables methods, counterfactual test, placebo test, and excluding the interference of other policies, the above results were still valid. Additionally, the dynamic effect shows that the inhibition effect of the SDPRP on the pollution emission intensity increased year by year. The influence mechanism analysis revealed that the SDPRP reduced the pollution emission intensity through technological innovation, digital transformation, and human capital. The effect of human capital was the strongest, while the influence of digital transformation was the weakest. The heterogeneity results show that the SDPRP was more effective in reducing emissions in declining resourcebased cities compared with mature resource-based cities. However, the SDPRP exacerbated the pollution emission intensity in growing resource-based cities, while the effect was not significant for regenerative resource-based cities. Furthermore, the SDPRP had a significantly greater effect on the pollution emission intensity in megacities than that in large cities and significantly contributed to the pollution emission intensity in smalland medium-sized cities. Based on the previous research results, the following policy implications are put forward. 
Resource-based cities should invest more in education to improve the education level of the workforce and train technical personnel for the new energy industry. At the same time, the concept of energy-saving and environmental protection should be popularized, and the traditional concepts of production and living should be transformed. In addition, policymakers in resource-based cities should also increase investment in research and innovation to promote the spread of environmental technology and cleaner production in enterprises. Furthermore, policymakers should promote the integration of Internet+ with the manufacturing industry and play an optimizing and integrating role in the allocation of social resources to continuously improve social productivity and creativity and reduce the dependence of cities on resources.

For different types of resource-based cities, policymakers should clarify the development direction and key tasks for each type of city to guide their respective scientific developments. For example, declining resource-based cities and mature resource-based cities should adjust their industrial structure, vigorously support new industries, and gradually enhance their sustainable development capacity. For regenerative resource-based cities, they should not only further open up to the outside world and improve the level of science and technology innovation, but also create ecologically livable cities and tourist cities by improving urban functions and enhancing urban tastes. For the growing resourcebased cities, policymakers should regulate the order of resource exploitation to determine the reasonable intensity of resource exploitation and improve the entry threshold of enterprises by implementing strict environmental regulations. The SDPRP is not recommended for small- and medium-sized cities without perfect supporting facilities. Megacities and large cities can further improve the policy system to promote the sustainable development of resource-based cities according to their urban characteristics to promote green transformation.

Although our study has some reference value, there are still some limitations. Pollution reduction has always been a key objective for resource-based cities to achieve sustainable development, but a deeper concern is how to make greater use of the positive effects of the SDPRP on pollution reduction in resource-based cities. For example, how to reasonably develop local resources according to the characteristics of the environmental carrying capacity of each resource-based city and guide the scientific development of each type of resource-based city categorically. Moreover, reducing pollution emission intensity while achieving a win-win situation for economic development and environmental management is also an important theoretical and practical issue that scholars should further investigate in the future. Furthermore, there are different realities within the settlements of large cities. In terms of the different functional districts within cities, they can be divided into commercial, residential, municipal, and public service, industrial, and technological districts. Furthermore, within different city functional districts, there may be significant differences in the impact of the SDPRP on pollution emission intensity. Therefore, a heterogeneity analysis based on intra-city characteristics such as the formation of technological districts on the impact of the SDPRP on pollution emission intensity could be one of the future research directions. Finally, there may be multiple impact pathways for the effect of the SDPRP on pollution emission intensity. In the future, the influencing mechanism of the SDPRP on pollution emission intensity can be explored from the perspective of finance.

Author Contributions: Conceptualization, Y.M. and L.L.; methodology, L.L. and Y.M.; software, X.Y.; validation, J.W., Y.M., and Q.R.; formal analysis, J.S.; investigation, Y.M.; resources, Y.M.; data curation, X.Y. and J.S.; writing—original draft preparation, Y.M.; writing—review and editing, X.Y.; supervision, J.S. All authors have read and agreed to the published version of the manuscript.

Funding: This research has been funded by the Project of National Natural Science Foundation of China (71463057), the Project of Natural Science Foundation of Xinjiang Uygur Autonomous Region (2017D01C071), and the Xinjiang Uygur Autonomous Region Postgraduate Innovation Project (XJ2019G005, XJ2020G020). The usual disclaimer applies.

Institutional Review Board Statement: Not applicable. 
Informed Consent Statement: Not applicable.

Data Availability Statement: All data generated or analyzed during this study are included in this published article.

Conflicts of Interest: The authors declare no conflict of interest.

\section{References}

1. Shi, T. Ecological economics in China: Origins, dilemmas and prospects. Ecol. Econ. 2002, 41, 5-20. [CrossRef]

2. Li, H.; Long, R.; Chen, H. Economic transition policies in Chinese resource-based cities: An overview of government efforts. Energy Policy 2013, 55, 251-260. [CrossRef]

3. Tang, Q.; Wang, J.; Jing, Z. Tempo-spatial changes of ecological vulnerability in resource-based urban based on genetic projection pursuit model. Ecol. Indic. 2021, 121, 107059. [CrossRef]

4. Takatsuka, H.; Zeng, D.Z.; Zhao, L. Resource-Based Regions, the Dutch Disease and City Development. 2012. Available online: https: / / www.rieti.go.jp/jp/publications/dp/13e001.pdf (accessed on 29 June 2021).

5. Yang, X.; Wu, H.; Ren, S.; Ran, Q.; Zhang, J. Does the development of the internet contribute to air pollution control in China? Mechanism discussion and empirical test. Struct. Chang. Econ. Dyn. 2021, 56, 207-224. [CrossRef]

6. Windsperger, J. Resource-based view of competitive advantage of cities. J. Econ. Bus. 2006, 2, 20-31.

7. Wang, Y.; Li, Y.; Zhu, Z.; Dong, J. Evaluation of green growth efficiency of oil and gas resource-based cities in China. Clean Technol. Environ. Policy 2021, 1-11. [CrossRef]

8. Yang, L.; Yang, L.; Ding, L.; Deng, F.; Luo, X.B.; Luo, S.L. Principles for the application of nanomaterials in environmental pollution control and resource reutilization. In Nanomaterials for the Removal of Pollutants and Resource Reutilization; Elsevier: Amsterdam, The Netherlands, 2019; pp. 1-23.

9. He, G.; Bao, K.; Wang, W.; Zhu, Y.; Li, S.; Jin, L. Assessment of ecological vulnerability of resource-based cities based on entropy-set pair analysis. Environ. Technol. 2021, 42, 1874-1884. [CrossRef]

10. Tan, J.; Lo, K.; Qiu, F.; Zhang, X.; Zhao, H. Regional economic resilience of resource-Based cities and influential factors during economic crises in China. Growth Chang. 2020, 51, 362-381. [CrossRef]

11. Wan, L.; Ye, X.; Lee, J.; Lu, X.; Zheng, L.; Wu, K. Effects of urbanization on ecosystem service values in a mineral resource-based city. Habitat Int. 2015, 46, 54-63. [CrossRef]

12. He, S.Y.; Lee, J.; Zhou, T.; Wu, D. Shrinking cities and resource-based economy: The economic restructuring in China's mining cities. Cities 2017, 60, 75-83. [CrossRef]

13. Zhang, M.; Tan, F.; Lu, Z. Resource-based cities (RBC): A road to sustainability. Int. J. Sustain. Dev. World Ecol. 2014, 21, 465-470. [CrossRef]

14. Li, L.; Lei, Y.; Pan, D.; Si, C. Research on sustainable development of resource-based cities based on the DEA approach: A case study of Jiaozuo, China. Math. Probl. Eng. 2016, 2016, 5024837. [CrossRef]

15. Zhao, M.; Zhang, X.; Wang, C.; Zhao, Y.; Wu, G. Research on Residents' Willingness to Pay for Promoting the Green Development of Resource-Based Cities: A Case Study in Chifeng. Sustainability 2021, 13, 2833. [CrossRef]

16. Yang, H.; Zhai, G.; Zhang, Y. Ecological vulnerability assessment and spatial pattern optimization of resource-based cities: A case study of Huaibei City, China. Hum. Ecol. Risk Assess. Int. J. 2020, 27, 606-625. [CrossRef]

17. Jing, Z.; Wang, J. Sustainable development evaluation of the society-economy-environment in a resource-based city of China: A complex network approach. J. Clean. Prod. 2020, 263, 121510. [CrossRef]

18. Murshed, S.M.; Serino, L.A. The pattern of specialization and economic growth: The resource curse hypothesis revisited. Struct. Chang. Econ. Dyn. 2011, 22, 151-161. [CrossRef]

19. Li, W.; Yi, P.; Zhang, D.; Zhou, Y. Assessment of coordinated development between social economy and ecological environment: Case study of resource-based cities in Northeastern China. Sustain. Cities Soc. 2020, 59, 102208. [CrossRef]

20. Xie, W.; Yan, T.; Xia, S.; Chen, F. Innovation or introduction? The impact of technological progress sources on industrial green transformation of resource-based cities in China. Front. Energy Res. 2020, 8, 598141. [CrossRef]

21. Chen, W.; Shen, Y.; Wang, Y. Evaluation of economic transformation and upgrading of resource-based cities in Shaanxi province based on an improved TOPSIS method. Sustain. Cities Soc. 2018, 37, 232-240. [CrossRef]

22. Gu, J.J.; Guo, P.; Huang, G.H.; Shen, N. Optimization of the industrial structure facing sustainable development in resource-based city subjected to water resources under uncertainty. Stoch. Environ. Res. Risk Assess. 2013, 27, 659-673. [CrossRef]

23. Guo, P.; Wang, T.; Li, D.; Zhou, X. How energy technology innovation affects transition of coal resource-based economy in China. Energy Policy 2016, 92, 1-6. [CrossRef]

24. Zhang, J.; Wang, J.; Yang, X.; Ren, S.; Ran, Q.; Hao, Y. Does local government competition aggravate haze pollution? A new perspective of factor market distortion. Socio-Econ. Plan. Sci. 2020, 100959. [CrossRef]

25. Qian, X.; Wang, D.; Wang, J.; Chen, S. Resource curse, environmental regulation and transformation of coal-mining cities in China. Resour. Policy 2019, 101447. [CrossRef]

26. More, T.; Stevens, T. Do user fees exclude low-income people from resource-based recreation? J. Leis. Res. 2000, 32, 341-357. [CrossRef]

27. Michaels, G. The long term consequences of resource-Based specialisation. Econ. J. 2011, 121, 31-57. [CrossRef] 
28. Qin, Y.; Lou, Y.; Lu, J.; Yin, L.; Yu, X. Simulation analysis of resource-based city development based on system dynamics: A case study of Panzhihua. Appl. Math. Nonlinear Sci. 2018, 3, 115-126. [CrossRef]

29. Song, X.M.; Kong, F.Z.; Zhan, C.S. Assessment of water resources carrying capacity in Tianjin City of China. Water Resour. Manag. 2011, 25, 857-873. [CrossRef]

30. Zhang, X.; Li, H. Urban resilience and urban sustainability: What we know and what do not know? Cities 2018, 72, 141-148. [CrossRef]

31. Yan, D.; Kong, Y.; Ren, X.; Shi, Y.; Chiang, S. The determinants of urban sustainability in Chinese resource-based cities: A panel quantile regression approach. Sci. Total Environ. 2019, 686, 1210-1219. [CrossRef]

32. Wang, D.; Shi, Y.; Wan, K. Integrated evaluation of the carrying capacities of mineral resource-based cities considering synergy between subsystems. Ecol. Indic. 2020, 108, 105701. [CrossRef]

33. Ruan, F.; Yan, L.; Wang, D. Policy effects on the sustainable development of resource-based cities in China: A case study of Yichun City. Resour. Policy 2021, 72, 102145. [CrossRef]

34. Ruan, F.; Yan, L.; Wang, D. The complexity for the resource-based cities in China on creating sustainable development. Cities 2020, 97, 102571. [CrossRef]

35. Yang, Y.; Guo, H.; Chen, L.; Liu, X.; Gu, M.; Ke, X. Regional analysis of the green development level differences in Chinese mineral resource-based cities. Resour. Policy 2019, 61, 261-272. [CrossRef]

36. Li, Q.; Liu, S.; Yang, M.; Xu, F. The effects of China's sustainable development policy for resource-based cities on local industrial transformation. Resour. Policy 2021, 71, 101940. [CrossRef]

37. Zeng, D.Z. How do special economic zones and industrial clusters drive China's rapid development. In Policy Research Working Papers; The World Bank: Washington, WA, USA, 2011.

38. Yang, Y.; Fang, Y.P.; Xu, Y.; Zhang, Y. Assessment of urban resilience based on the transformation of resource-based cities: A case study of Panzhihua, China. Ecol. Soc. 2021, 26, 20. [CrossRef]

39. Yu, Y.; Zhang, N. Does smart city policy improve energy efficiency? Evidence from a quasi-natural experiment in China. J. Clean. Prod. 2019, 229, 501-512. [CrossRef]

40. Yigitcanlar, T.; Kamruzzaman, M. Planning, development and management of sustainable cities. Sustainability 2015, 7, 1467714688. [CrossRef]

41. Qiping, R. Circular economy action programs and countermeasures for small and medium-sized resource-based cities of China-case study of Zibo city of Shandong province. Energy Procedia 2011, 5, 2183-2188. [CrossRef]

42. Rahman, M.M.; Alam, K. Clean energy, population density, urbanization and environmental pollution nexus: Evidence from Bangladesh. Renewable Energy. 2021, 172, 1063-1072. [CrossRef]

43. Attour, A.; Burger-Helmchen, T.; Zhong, J.; Nieminen, M. Resource-based co-innovation through platform ecosystem: Experiences of mobile payment innovation in China. J. Strategy Manag. 2015, 8, 283-298.

44. Wu, H.; Hao, Y.; Ren, S.; Yang, X.; Xie, G. Does internet development improve green total factor energy efficiency? Evidence from China. Energy Policy 2021, 153, 112247. [CrossRef]

45. Xing, M.; Luo, F. Comparative Study on the Optimization Path of Industrial Value Chain in China's Resource-Based Cities. Sustainability 2018, 10, 1338. [CrossRef]

46. Millar, C.C.; Choi, C.J. Development and knowledge resources: A conceptual analysis. J. Knowl. Manag. 2010, 14, 759-776. [CrossRef]

47. Ayadi, O.F.; Saffu, K.; Apori, S.O.; Elijah-Mensah, A.; Ahumatah, J. The contribution of human capital and resource-based view to small- and medium-sized tourism venture performance in Ghana. Int. J. Emerg. Mark. 2008, 3, 268-284.

48. Oduse, S.; Zewotir, T.; North, D. The impact of antenatal care on under-five mortality in Ethiopia: A difference-in-differences analysis. BMC Pregnancy Childbirth 2021, 21, 44. [CrossRef] [PubMed]

49. Jia, R.; Shao, S.; Yang, L. High-speed rail and CO2 emissions in urban China: A spatial difference-in-differences approach. Energy Econ. 2021, 99, 105271. [CrossRef]

50. Nawaz, M.A.; Seshadri, U.; Kumar, P.; Aqdas, R.; Patwary, A.K.; Riaz, M. Nexus between green finance and climate change mitigation in N-11 and BRICS countries: Empirical estimation through difference in differences (DID) approach. Environ. Sci. Pollut. Res. 2021, 28, 6504-6519. [CrossRef] [PubMed]

51. Baron, R.M.; Kenny, D.A. The moderator-mediator variable distinction in social psychological research: Conceptual, strategic, and statistical considerations. J. Personal. Soc. Psychol. 1986, 51, 1173-1182. [CrossRef]

52. Hao, Y.; Ye, B.; Gao, M.; Wang, Z.; Chen, W.; Xiao, Z.; Wu, H. How does ecology of finance affect financial constraints? Empirical evidence from Chinese listed energy-and pollution-intensive companies. J. Clean. Prod. 2020, 246, 119061. [CrossRef]

53. Song, L.; Jing, J.; Yan, Z.; Sun, C. Does government information transparency contribute to pollution abatement? Evidence from 264 Chinese cities. Environ. Sci. Pollut. Res. 2021, 1-11. [CrossRef]

54. Wu, H.; Hao, Y.; Ren, S. How do environmental regulation and environmental decentralization affect green total factor energy efficiency: Evidence from China. Energy Econ. 2020, 91, 104880. [CrossRef]

55. Karimian, H.; Li, Q.; Chen, H.F. Assessing urban sustainable development in Isfahan. Appl. Mech. Mater. 2012, 253, 244-248. [CrossRef]

56. Zinatizadeh, S.; Azmi, A.; Monavari, S.M.; Sobhanardakani, S. Evaluation and prediction of sustainability of urban areas: A case study for Kermanshah city, Iran. Cities 2017, 66, 1-9. [CrossRef] 
57. Yang, X.; Zhang, J.; Ren, S.; Ran, Q. Can the new energy demonstration city policy reduce environmental pollution? Evidence from a quasi-natural experiment in China. J. Clean. Prod. 2021, 287, 125015. [CrossRef]

58. Usman, A.; Ozturk, I.; Hassan, A.; Zafar, S.M.; Ullah, S. The effect of ICT on energy consumption and economic growth in South Asian economies: An empirical analysis. Telemat. Inform. 2021, 58, 101537. [CrossRef]

59. Pan, X.; Li, M.; Pu, C.; Xu, H. Study on the industrial structure optimization under constraint of energy intensity. Energy Environ. 2021, 32, 134-151. [CrossRef]

60. Zhang, M.; Liu, X.; Ding, Y. Assessing the influence of urban transportation infrastructure construction on haze pollution in China: A case study of Beijing-Tianjin-Hebei region. Environ. Impact Assess. Rev. 2021, 87, 106547. [CrossRef]

61. Rjoub, H.; Odugbesan, J.A.; Adebayo, T.S.; Wong, W.K. Sustainability of the moderating role of financial development in the determinants of environmental degradation: Evidence from Turkey. Sustainability 2021, 13, 1844. [CrossRef]

62. Johnstone, N.; Haščič, I.; Kalamova, M. Environmental policy design characteristics and technological innovation: Evidence from patent data. OECD Environ. Work. Pap. 2010. [CrossRef]

63. Ozcan, B.; Apergis, N. The impact of internet use on air pollution: Evidence from emerging countries. Environ. Sci. Pollut. Res. 2018, 25, 4174-4189. [CrossRef]

64. Khan, Z.; Ali, S.; Dong, K.; Li, R.Y.M. How does fiscal decentralization affect $\mathrm{CO}_{2}$ emissions? The roles of institutions and human capital. Energy Econ. 2021, 94, 105060. [CrossRef]

65. Qi-ying, R.; Jin-ning, Z.; Xiao-dong, Y. Does High-Speed Railway Improve the Efficiency of Urban Green Development-An Empirical Test Based on Difference in Difference Model. J. Guizhou Univ. Financ. Econ. 2020, 38, 100-110.

66. Zhang, X.; Qu, M. Impact of Environmental Regulation on Scientific and Technological Competitiveness of Resource-Based Cities in China-Based on Panel Data of 33 Resource-Based Cities. Int. J. Environ. Res. Public Health 2020, 17, 9187. [CrossRef] [PubMed]

67. Lu, C.; Deng, Q.H.; Liu, W.W.; Huang, B.L.; Shi, L.Z. Characteristics of ventilation coefficient and its impact on urban air pollution. J. Cent. South Univ. 2012, 19, 615-622. [CrossRef]

68. Tang, K.; Liu, Y.; Zhou, D.; Qiu, Y. Urban carbon emission intensity under emission trading system in a developing economy: Evidence from 273 Chinese cities. Environ. Sci. Pollut. Res. 2021, 28, 5168-5179. [CrossRef]

69. Cao, J.; Law, S.H.; Samad, A.R.B.A.; Mohamad, W.N.B.W.; Wang, J.; Yang, X. Impact of financial development and technological innovation on the volatility of green growth-evidence from China. Environ. Sci. Pollut. Res. 2021, 1-17. [CrossRef]

70. Yu, C.; de Jong, M.; Cheng, B. Getting depleted resource-based cities back on their feet again-the example of Yichun in China. J. Clean. Prod. 2016, 134 Pt A, 42-50. [CrossRef]

71. Zeng, D.-Z.; Zhao, L. Pollution havens and industrial agglomeration. J. Environ. Econ. Manag. 2009, 58, 141-153. [CrossRef] 